\title{
A comparison between pylorus-preserving and distal gastrectomy in surgical safety and functional benefit with gastric cancer: a systematic review and meta- analysis
}

\section{Xinyu Mao}

Nanjing Medical University Second Affiliated Hospital

Xinlei Xu

Nanjing Medical University Second Affiliated Hospital

Hua Zhu

Nanjing Medical University Second Affiliated Hospital

Chunpeng Ji

Nanjing Medical University Second Affiliated Hospital

Xu Lu

Nanjing Medical University Second Affiliated Hospital

Baolin Wang ( $\sim$ wangbl@njmu.edu.cn )

Nanjing Medical University Second Affiliated Hospital https://orcid.org/0000-0001-9758-4134

Research article

Keywords: Pylorus-preserving gastrectomy, Distal gastrectomy, Early gastric cancer, Meta-analysis

Posted Date: February 13th, 2020

DOI: https://doi.org/10.21203/rs.2.23508/v1

License: (9) This work is licensed under a Creative Commons Attribution 4.0 International License. Read Full License

Version of Record: A version of this preprint was published at World Journal of Surgical Oncology on July 8th, 2020. See the published version at https://doi.org/10.1186/s12957-020-01910-y. 


\section{Abstract}

Background: Due to better functional outcomes, pylorus-preserving gastrectomy (PPG) has been widely applied for early gastric cancer (EGC) patients as an alternative to distal gastrectomy (DG). However, controversies still persist regarding the surgical efficacy and oncological safety of PPG.

Methods: Original studies compared PPG and DG for EGC were searched in PubMed, Embase and the Cochrane Register of Controlled Trials up to December 2019. The weight mean difference, standardized mean difference or odds risk were used to calculate the short-term and long-term outcomes between the two groups.

Results: Twenty-one non-randomized controlled studies comprising 4871 patients (1955 in the PPG group and 2916 in the DG group) were enrolled in this systematic review and meta-analysis. PPG showed longer hospital day, decreased harvested lymph nodes and more delayed gastric emptying. However, PPG had the benefits of lower incidence of anastomosis leakage, early dumping syndrome, gastritis and bile reflux and better recovery of total protein, albumin. hemoglobin and weight. No difference was found in operative time, blood loss and overall complications. Moreover, the long-term survival and recurrence rate were similar in two groups.

Conclusion: Owing to the non-inferiority of surgery and oncology outcomes and the superiority of function outcomes in PPG, we revealed that PPG can be clinically applicable instead of DG in EGC. However, more highquality comparative studies and randomized clinical trials (RCTs) would be required for further confirmation.

\section{Background}

The development of cancer screening programs and the popularization of endoscopic techniques have allowed the increasing proportion of early gastric cancer(EGC), particularly in Korea and Japan[1, 2]. Radical gastrectomy with D2 lymphadenectomy was recommended as the gold standard treatment for EGC, and distal gastrectomy (DG) is one such conventional surgical procedure. Due to the excellent oncological outcomes of early gastric cancer, restoration of stomach function and better postoperative quality of life were recognized as important as the radical curability of primary tumor. Pylorus-preserving gastrectomy (PPG), which considered as a representative example of function-preserving gastrectomy, had become an alternative to distal gastrectomy for the treatment of EGC. Since the first application of PPG in 1967[3], this approach has been introduced as a minimally invasive surgery and even extended to combine with laparoscopic technique. Moreover, the retainment of pyloric cuff and vagal nerve in PPG provided advantages such as ameliorating postoperative gastritis, bile reflux, early dumping syndromes and improving nutritional status $[4,5]$. In PPG, the infra-pyloric LNs are routinely dissected with preserving the infra-pyloric vessels, and the supra-pyloric LNs are usually omitted to preserve the right gastric artery and the hepatic branch of the vagal nerve[6, 7]. However, technically difficulty and incomplete lymph resection, which raise concerns about compromising long-term survival, contribute to the restriction on extensive application of PPG.

Although many studies comparing PPG and DG in terms of surgical and functional outcomes have been published[7-9], whether PPG is better than DG for EGC without compromising oncological safety remains debatable because of lacking long-term oncologic outcomes and high-level evidence of RCTs. The first metaanalysis, which was published in 2014[10], demonstrated that PPG had superior benefits in terms of lower incidence rates of early dumping syndrome, gastritis, and bile reflux as well as regaining of weight. According 
to the Japanese gastric cancer treatment guidelines and considerable newly published studies with relatively comprehensive data, indications as well as standardized management and treatment for PPG have been well established. Therefore, we performed an updated meta-analysis to demonstrate the surgery efficacy, oncologic safety and function recovery of PPG.

\section{Methods}

\section{Literature search}

A systematic literature search was carried out up to December 2019 using the following database: PubMed, Embase and the Cochrane Register of Controlled Trials (CENTRAL). The searches were limited to studies published in English. The search terms were as follows: "gastric cancer or stomach cancer or stomach neoplasm or gastric neoplasm" and "pylorus-preserving or pylorus preserving or function-preserving or function preserving". Two independent reviewers (Xinyu Mao and Xinlei Xu) carefully explored related citations of the retrieved reports to prevent potential additional articles from overlooking. This meta-analysis was conducted according to the Preferred Reporting Items for Systematic Reviews and Meta-Analyses (PRISMA) statement[11].

\section{Inclusion and exclusion criteria}

Inclusion criteria: (1) studies of patients with pathologically confirmed early gastric cancer; (2) compared pylorus-preserving gastrectomy with distal gastrectomy; (3) both open and laparoscopic procedure; (4) any kind of comparative studies; (5) revealed adequate data of the surgical or functional outcomes.

Exclusion criteria: (1) overlapped publications or duplicated data; (2) reviews, case reports, comments and conference abstracts; (3) not addressing the comparison between pylorus-preserving gastrectomy and distal gastrectomy; (4) not relevant or available data of target endpoints.

\section{Data extraction and Quality assessment}

Two authors independently conducted the data extraction among all enrolled studies; including (1) study characteristics (authors; year; country; study design; sample size); (2) patients characteristics (age, sex; ASA; $\mathrm{BMl}$; tumor size; tumor stage; tumor location; reconstruction type; proximal and distal resection margin); (3) surgical outcomes (operation time; blood loss; hospitalization day; examined lymph nodes) and postoperative complications (such as anastomosis leakage; bile reflux; gastritis; delayed gastric emptying; dumping syndrome and gallbladder stones); (4) functional status (total protein; albumin; body weight and hemoglobin) and long-term oncological outcomes ( survival and recurrence rates). Any disagreements were resolved with discussion in conference by two independent researchers.

The Newcastle-Ottawa Quality Assessment Scale (NOS) checklist (Additional file 1), which consisted of three categories (selection, comparability and outcome) and eight elements with a maximum score of nine, was used to evaluate the quality of enrolled observational research. Studies graded with 7 or more stars were considered as high-quality.

\section{Statistical analysis}


Odds ratio (OR), weight mean difference (WMD) and standardized mean difference (SMD) presented with 95\% confidence interval $(\mathrm{Cl})$ were used to pool analysis dichotomous and continuous variables, respectively. When the reports included in our work only report mean and range, standard deviation (SD) was estimated based on the formulas reported by Hozo et al.[12] Overall survival (OS) was measured with the hazard ratio (HR) and 95\% Cl which calculated by Engauge Digitizer Version 4.1 according to the Kaplan-Meier survival curves.

Heterogeneity was assessed by the chi-squared-based Q test and Higgins l-squared test among studies. According to the high heterogeneity with $R>50 \%$ or $p<0.1$, random effects model was chosen. On the contrary, fixed effects model was preferred in terms of appreciable heterogeneity. According to the study characteristics, we performed the subgroup-analyses to explore the potential cause of the heterogeneity. Funnel plots and Egger's test was used for evaluation of publication bias. We used trim-and-fill test to estimate the influence on the results of public bias. ALL analyses were carried out with Stata software (version 15; Stata Corp LLC, College Station, TX).

\section{Results}

\section{Literature search}

A total of 956 studies were identified in accordance with The Preferred Reporting Items for Systematic Reviews and Meta-Analyses (PRISMA) flow diagram (Fig.1). After removing 173 duplicates, 647 non-relevant studies were initially excluded by carefully screening the title and or abstract, and subsequently 109 articles were evaluated for eligibility via cautiously reviewing full-text and statistical data. Finally, 21 non-RCTs[4-9, 13-27] with 4871 patients were included in the quantitative Synthesis.

\section{Study characteristics}

The details of these 21 comparative studies included in the meta-analysis are shown in Table 1. Among enrolled studies, 7 were performed laparoscopically and open surgery was operated in the other fourteen studies, of which $96.9 \%$ patients were pathologically diagnosed with stage I gastric cancer. Sixteen papers were reported by Japan, and only 5 studies were published by Korea and China.

Additional file 2 showed the analysis of demographic characteristics. The gender distribution in the PPG group were significantly different in both groups $(\mathrm{OR}=0.83,95 \% \mathrm{Cl}=0.73-0.94,2=0.00 \%, p=0.005)$, and no difference in articles compared age $(\mathrm{WMD}=0.19,95 \% \mathrm{Cl}=-1.71-2.09, R=87.90 \%, p=0.845)$ and $\mathrm{BMI}$ was demonstrated between two groups (WMD $=-0.02,95 \% \mathrm{Cl}=-0.24-0.19, R=0.00 \%, p=0.828)$. What's more, similar tumor size was observed in enrolled researches $(\mathrm{WMD}=0.02,95 \% \mathrm{Cl}=-0.09-0.13, R=31.50 \%, p=0.767)$. After quality assessment with nine-star Newcastle-Ottawa Scale, 18 reports which were identified as high-quality studies, were included in this meta-analysis and NOS scores were presented in Additional file 3.

\section{Intraoperative and postoperative findings}

Both procedures demonstrated comparatively results regarding operation time $(\mathrm{WMD}=-5.00,95 \% \mathrm{Cl}=-13.53-$ $3.54, R=76.30 \%, p=0.251$ ) (Fig. $2 \mathrm{~A}$ ) and blood loss (WMD $=-19.85,95 \% \mathrm{Cl}=-45.14-5.44, R=74.90 \%, p=0.124)$ (Fig. 2B)between the PPG and DG group. However, we observed significantly fewer retrieved lymph nodes 
among the two groups (WMD $=-1.10,95 \% \mathrm{Cl}=-2.18--0.01, P=8.70 \%, p=0.048)$ (Fig. 2C), which was also found with the dissection or the preservation of No.5 lymph nodes. We also found longer hospital duration in PPG group (WMD $=0.98,95 \% \mathrm{Cl}=0.66-1.29, R=30.60 \%, p=0.000)$ (Fig. 2D). However, the PPG group had a significantly shorter proximal resection margin and distal resection margin compared to $D G$ group $\left(\mathrm{WMD}=-0.47,95 \% \mathrm{Cl}=-0.91--0.03, P^{2}=74.30 \%, p=0.038 ; \mathrm{WMD}=-2.76,95 \% \mathrm{Cl}=-4.96--0.57, P^{2}=98.20 \%, p=0.013\right)$.

\section{Morbidity and mortality}

This meta-analysis demonstrated that there was no significant difference in the incidence of postoperative complications ( $\mathrm{OR}=0.97,95 \% \mathrm{Cl}=0.76-1.25, R=5.70 \%, p=0.835$ ) (Fig. 2E). According to anastomotic leakage, difference was found significant in PPG $(\mathrm{OR}=0.49,95 \% \mathrm{Cl}=0.24-0.97, P=0.00 \%, p=0.041)$ (Fig. 2F). In addition, there were significantly differences in delayed gastric emptying ( $O R=1.88,95 \% \mathrm{Cl}=1.23-2.87, R=38.40 \%$, $p=0.003$ ) (Fig. 3A), which was also confirmed by assessing gastric emptying times (WMD $=8.86,95 \% \mathrm{Cl}=1.71-$ $16.00, P=0.00 \%, p=0.015)$. What's more, $\mathrm{PPG}$ group revealed similar gallbladder stones rate $(\mathrm{OR}=0.63$ $95 \% \mathrm{Cl}=0.38-1.03, P=14.60 \%, p=0.063)$ (Fig. 3B), but lower incidence of early dumping syndrome (OR=0.18, $95 \% \mathrm{Cl}=0.07-0.44, R=0.00 \%, p=0.000)$. In terms of postoperative endoscopic findings and symptoms(Additional file 4), Patients performed with PPG procedure suffered fewer gastritis and bile regurgitation $(\mathrm{OR}=0.22,95 \% \mathrm{Cl}=0.07-0.74, P=71.30 \%, p=0.014 ; \mathrm{OR}=0.3095 \% \mathrm{Cl}=0.10-0.89, P=57.90 \%$, $p=0.031)$, which was not found in esophagitis (OR=1.21, 95\% Cl=0.56-2.61, $R=37.90 \%, p=0.621)$.

\section{Long-term oncological and nutritional outcomes}

Discrepancy was not found on the overall survival rate described by three included studies (WMD $=0.63$, $95 \% \mathrm{Cl}=-0.06-1.32, P=0.00 \%, p=0.074)$, and patients receiving PPG did not have a higher incidence of recurrence ( $\mathrm{OR}=1.41,95 \% \mathrm{Cl}=0.68-2.89, P=0.00 \%, p=0.355)$ (Additional file 5$)$. As shown in Figure 3 , the serum total protein and albumin level in patients with PPG were higher compared with those with DG (SMD $=0.39$, $95 \% \mathrm{Cl}=0.25-0.53, P=34.60 \%, p=0.000 ; \mathrm{SMD}=0.31,95 \% \mathrm{Cl}=0.17-0.44, P=22.00 \%, p=0.000)$. Hemoglobin investigated in five articles showed better recovery $(\mathrm{SMD}=0.55,95 \% \mathrm{Cl}=0.39-0.71, R=0.00 \%, p=0.000)$. Moreover, PPG was found a better selection with fewer decreased body weight $(\mathrm{WMD}=3.24,95 \% \mathrm{Cl}=1.79-4.69$, $R=65.30 \%, p=0.000)$.

\section{Subgroup analysis}

According to year of publication, study type and operation procedure, subgroup analysis was performed to explanation heterogeneity and evaluate the possible effect of these parameters (Table 3). Shorter operative time and less blood loss of PPG was only detected in the prospective studies. Significant differences were observed in gastritis in the retrospective studies, the studies with laparoscopic procedure and the studies before 2010. Delayed gastric emptying was associated with the retrospective studies, the studies with open surgery and the studies after 2010 . What's more, in terms of postoperative body weight change, we observe significant differences in all subgroup analysis

\section{Sensitivity and Publication Bias}


Possibility of publication bias was detected with constructing funnel plots and Egger's linear regression test. We did not find significant publication bias expect for gastritis and body weight change (Fig. 4, Fig. 5 and Additional file 6). However, trim-and -fill test indicated the stability of this results. Furthermore, Galbraith plot was used to assess every individual study which account for the heterogeneity, and similar results were observed after exclusion of these researches in the supplemental information (Additional file $7,8,9$ ).

\section{Discussion}

Since the first report on the PPG for the treatment of gastric ulcer was published in 1967[3], the indication of this procedure has been broadened to early gastric cancer[28, 29]. Moreover, this procedure was often performed with laparoscopic approach as less-invasive surgery. In addition, PPG is recommended for cT1N0M0 gastric cancer located in the middle-third of the stomach according to Japanese Gastric Cancer Treatment Guideline[30]. Although numerous published studies that confirmed the non-inferiority of surgical outcomes and better function status of PPG, controversies still exist without the evidence of high-quality RCTs. The ongoing KLASS-04 (NCT No.02595086) comparing LAPPG and LADG for EGC is expected to provide conclusive evidence. Therefore, this meta-analysis is aimed to assess the value of PPG and compare with the final results of KLASS-04.

The first meta-analysis published in 2014 included 16 studies with 1774 patients and demonstrated that PPG provided the benefits of preventing early dumping syndrome, bile reflux and gastritis[10]. Given more additional articles published to compare PPG with DG for early gastric cancer, we accordingly performed an updated meta-analysis to corroborates surgical safety, oncological efficacy and better function status for PPG.

Moreover, depending on the published date, study design and surgical procedure, we grouped enrolled studies

to compare PPG and DG more precisely. Additionally, we matched factors such as the length of antral cuff and the vagus nerve preserved that might influence postoperative outcomes like gastritis and DGE. Furthermore, long-term oncological adequacy published with three studies followed for more than three years and function outcomes (total protein, albumin, hemoglobin and body weight loss) were particularly evaluated on the comparison of PPG versus and DG. To the best of knowledge, this is the biggest sample size meta-analysis and systematic review on PPG and DG including long-term oncological and functional outcomes up to date.

This meta-analysis presented that similar operation duration and blood loss was observed between PPG and DG. Interestingly, shorter operative time and lesser blood loss were associated with PPG in several prospective cohort studies $[5,8]$ with subgroup analysis. This phenomenon may be explained by the relatively few prospective articles and small sample size. However, shorter operating time and blood loss may be noted after the accumulation of PPG experience, but further big-sample researches or RCTs are needed. Additionally, postoperative hospitalization is a very important indictor in recovery and hospital expenses. We found that PPG had the disadvantage of longer hospital day, which was also demonstrated in the subcategory analysis except for the prospective cohort studies. The same reason as decreased operation time and blood loss may can account for exception of the prospective studies. This revealed that PPG allows for delaying earlier recovery in both laparoscopic and open operation.

Owing to the skepticism regarding the incomplete lymphadenectomy, the oncological safety remains as the main issue, and the number of retrieved lymph nodes is related to the long-term survival. However, the 
harvested lymph nodes in PPG was significantly lesser than in conventional DG, which can be attributed to incomplete dissection of supra-pyloric (5) and infra-pyloric (6) lymph nodes in PPG. The outcomes of the studies after 2010 and the prospective cohort studies were in favor of (in line with) (showed a favorable trend toward $==$ reach the same conclusion) DG. The disparity might be explained by the difference in preserving N0.5 lymph nodes. The preserving of No.5 lymph nodes was usually performed in the studies after 2010 but omitted in the studies before 2010. Furthermore, there was significant difference of dissected lymph nodes in studies with the preservation of No.5 lymph nodes. Lack of N0.5 lymph nodes station is considered to preserve the right gastric artery and pyloric branch of vagal nerve, and preserving the infra-pyloric artery may lead to incomplete No.6 LN dissection. Given the relatively easy technique of dissecting infra-pyloric lymph nodes with infra-pyloric artery preservation, all studies enrolled in this meta-analysis from 2017 to 2019 radically resected LN station 6 but omitted (leaved) LN station 5, which bring about incomplete D1 lymphadenectomy and concerns over oncological safety. Despite the significantly lower number of retrieved LNs in PPG, long-term survival rates were comparable for both groups in the meta-analysis. One possible explanation was the low metastasis rate of supra-pyloric lymph nodes in EGC. Additionally, As described in a Korean report, the incidence of lymph node metastasis at the LN station 5 was $0.45 \%$ (1/220)[31]. A study of 219 cases revealed only a $0.46 \%$ metastasis rate of supra-pyloric stations for gastric cancer invading mucosal or submucosal[32]. Oh et al. reported that the metastasis rate to supra-pyloric nodes was $4.2 \%(52 / 1245)[33]$.

According to the current version of the Japanese Gastric Cancer Treatment Guidelines[30], patients with cT1N0M0 gastric cancer located in the middle one-third of the stomach and at least $4.0 \mathrm{~cm}$ away from the pylorus can be candidates for PPG. This corroborates that PPG have a similar oncologic safety for intramucosal or submucosal carcinoma without on evidence of metastasis. However, in clinically practice, the indication of PPG was broadened to T2a cancers with no evidence of lymph metastasis. Kong et al. [32]suggested that T1a and T2a cancers of the $\geq 6$ DRM group showed no metastasis to LNS 5 and supported pylorus-preserving gastrectomy as a safe treatment for T2a cases with preoperatively diagnosed as T1. Supporting this result, one retrospective study reported on better prognoses of T2 gastric cancers that were diagnosed preoperatively as T1 than the other T2 cancers[34].Nevertheless, further validations are needed to expand the indication for PPG in T2a cancers.

Due to preservation of the infra-pyloric vessels and hepatic branch of the vagus nerve, PPG has the advantage of better pyloric function and quality of life. Although similar postoperative overall complications were observed in both procedures, fewer anastomotic leakages were found in the PPG groups while the analysis of subgroup did not reach any significant differences (the benefits of PPG were not found in the subcategory analyses). The decreased anastomotic fistula may be associated with better blood supply and function recovery. As described in previous reports[35], several risk factors such as advanced age, anemia and malnourishment were associated with anastomotic leakage. In our experience, reducing the anastomosis tension and ensuring the blood supply extremity have a beneficial effect on the healing of anastomosis, whether or not patients are in a good physical condition. For patients with PPG, higher hemoglobin level might be partly responsible for this result, as well as retaining the tissue around anastomosis and leaving the right gastric artery and the infra-pyloric artery. Thereby, PPG have a similar or even better short-term technical safety compared with DG, but this result should be corroborated by the final outcomes of large-scale RCTs. 
Moreover, fewer patients in PPG group suffered from postoperative early dumping syndromes. The mechanisms of early dumping syndromes have yet to been confirmed. Probably, the resection of pyloric and/or vagus nerve might be associated with this phenomenon[36], and this is why there are a clear distinction between PPG patients and DG patients. However, few studies after 2010 have tried to report this complication after PPG and a standard definition and diagnostic criteria of early dumping syndromes are yet to be identified.

In addition, compromising hepatic and pyloric branches of the vagus nerve can increase the incidence of gallstones. In PPG, the physiological reconstruction without vagotomy maintain the contraction of Oddi sphincter and secretion of cholecystokinin[37,38]. Whereas, the risk of gallstones formation was decreased in the PPG group but with no significantly in comparison with DG.

What's more, the most frequent postoperative dysfunction in PPG was generally thought as delayed gastric emptying (DGE), and similar phenomenon was observed in our analysis. More DGE were found in the PPG group in the studies after 2010, the retrospective studies and studies performed with LPPG. This result may be caused by lesser extent of gastric resection, and subsequently the remaining pylorus and remnant stomach can develop postprandial fullness and dyspepsia. The rate of DGE was also thought to be associated with the length of antral cuff. The influence of the antral cuff on DGE was also investigated in our meta-analysis, in which studies with an antral cuff length of $>3 \mathrm{~cm}$ showed a significantly higher incidence of DGE but studies with the antral cuff maintained $<3 \mathrm{~cm}$ did not reach a level of significance. Owing to just one articles with $<$ $3 \mathrm{~cm}$ antral cuff was published, the results may be influenced by the relatively small sample size. Additionally, the incidence of gastric stasis was lower with preservation of infra-pyloric blood supply in conventional pylorus-preserving gastrectomy (cPPG), which ranged from 5.7-8.0\% reported previously[7, 9, 39, 40]. Kiyokawa et al. showed that no DGE patient was found with the preservation of infra-pyloric vein, while $8.5 \%$ patients from the cPPG group[40]. Moreover, intraoperative manual dilatation of pylorus also significantly reduced the DGE rate. The DGE rate in the CPPG group (8.6\%) was significantly higher to that with manual dilatation (1.1\%) among a total of 232 patients[41]. Therefore, the manual pyloric dilatation as well as preservation of infra-pyloric vessels might be an important step to minimize the most disturbing complications.

Postoperative endoscopic finding in this meta-analysis showed a favorable trend toward PPG. The incidence of gastritis and bile regurgitation were significantly lower in PPG group, but significant difference in esophagitis was not found. We think the most important factor was the reduction of the range of gastrectomy and retainment of pylorus function.

It was generally expected that PPG would improve nutrition index and decrease weight loss. (Significantly lower values) For PPG cases, the recovery of total protein, albumin and hemoglobin were significantly better than DG cases. More extent of gastrectomy considerably reduced absorption and reservoir function of stomach such as the secretion of gastric acid, and resection of the vagus nerve also influence the peristalsis of stomach and duodenum. In the subgroup analysis,

PPG leads to significantly better function outcomes except the studies before 2010 had a similar albumin level compared with DG. For nutritional assessment, body weight loss was also a useful indictor and the lower decreased rate of body weight was seen in our studies and subgroup analysis due to the similar reasons as above-mentioned. 
This meta-analysis had several limitations. First, given no randomized controlled published to compare PPG and DG, only non-randomized controlled trials were enrolled in this study, and the inherent selection bias reduced the level of evidence. Second, all the participants in this meta-analysis were enrolled in the East Asia, therefore the results should be carefully generalizable(extrapolated) to Western countries. Third, publication bias with Egger's test was found in gastritis and body weight loss while not performed on parameters with insufficient studies. Despite performing considerable stratification analyses, we could not fully eliminate the statistical heterogeneity. Fourth, total protein, albumin and hemoglobin were analyzed by SMD because of different assessment methods. Thus, large-scale RCTs compared with PPG and DG are needed to further corroborate these conclusions.

\section{Conclusion}

PPG is a feasible and safe option for early gastric cancer due to similar clinical effects as compared with DG. PPG was associated with longer hospital day, decreased lymph nodes retrieval and more DGE, but with the benefits of decreased risk of anastomotic leakage, early dumping syndrome, gastritis and bile reflux and preventing the deficiency of total protein, albumin and hemoglobin and the loss of weight. Moreover, the operation time, the blood loss and the long-term survival rate were similar between two groups. However, these observations need to be confirmed by well-designed multicenter RCTs.

\section{Abbreviations}

PPG: pylorus-preserving gastrectomy; DG: distal gastrectomy; EGC: early gastric cancer; RCT: randomized clinical trial; OR: Odds ratio; WMD: weight mean difference; SMD: standardized mean difference; Cl: confidence interval; SD: standard deviation; HR: hazard ratio; OS: overall survival; DGE: delayed gastric emptying; CPPG: conventional pylorus-preserving gastrectomy

\section{Declarations}

\section{Ethics approval and consent to participate}

Not applicable.

\section{Consent for publication}

Not applicable.

\section{Availability of data and materials}

The datasets supporting the conclusions of this article are included within the article and its additional files.

\section{Competing interests}

The authors declare that they have no conflict of interest.

\section{Funding}


There was no sponsor for this study.

\section{Authors' contributions}

XM was the major contributor in data collection, data analysis and manuscript writing. XX contributed to data collection and analysis. BW was the major contributors of design of the study. $\mathrm{HZ}$, CJ and XL were substantially involved in data check and data analysis. All authors read and approved the final manuscript.

\section{Acknowledgements}

No applicable.

\section{Author details}

1 Department of General Surgery, The Second Affiliated Hospital of Nanjing Medical University, Nanjing 210011, Jiangsu, China

\section{References}

1. Information Committee of Korean Gastric Cancer A: Korean Gastric Cancer Association Nationwide Survey on Gastric Cancer in 2014. Journal of gastric cancer 2016, 16(3):131-140.

2. Lee KJ, Inoue M, Otani T, Iwasaki M, Sasazuki S, Tsugane S, Group JS: Gastric cancer screening and subsequent risk of gastric cancer: a large-scale population-based cohort study, with a 13-year follow-up in Japan. International journal of cancer 2006, 118(9):2315-2321.

3. Maki T, Shiratori T, Hatafuku T, Sugawara K: Pylorus-preserving gastrectomy as an improved operation for gastric ulcer. Surgery 1967, 61(6):838-845.

4. Park DJ, Lee HJ, Jung HC, Kim WH, Lee KU, Yang HK: Clinical outcome of pylorus-preserving gastrectomy in gastric cancer in comparison with conventional distal gastrectomy with Billroth I anastomosis. World $J$ Surg 2008, 32(6):1029-1036.

5. Zhu CC, Cao H, Berlth F, Xu J, Park SH, Choe HN, Suh YS, Kong SH, Lee HJ, Kim WH et al: Pyloruspreserving gastrectomy for early cancer involving the upper third: can we go higher? Gastric Cancer 2019, 22(4):881-891.

6. Imada T, Rino Y, Takahashi M, Suzuki M, Tanaka J, Shiozawa M, Kabara K, Hatori S, Ito H, Yamamoto Y et al: Postoperative functional evaluation of pylorus-preserving gastrectomy for early gastric cancer compared with conventional distal gastrectomy. Surgery 1998, 123(2):165-170.

7. Xia X, Xu J, Zhu C, Cao H, Yu F, Zhao G: Objective evaluation of clinical outcomes of laparoscopy-assisted pylorus-preserving gastrectomy for middle-third early gastric cancer. BMC Cancer 2019, 19(1):481.

8. Shibata C, Shiiba KI, Funayama Y, Ishii S, Fukushima K, Mizoi T, Koyama K, Miura K, Matsuno S, Naito H et al: Outcomes after pylorus-preserving gastrectomy for early gastric cancer: a prospective multicenter trial. World J Surg 2004, 28(9):857-861.

9. Suh YS, Han DS, Kong SH, Kwon S, Shin Cl, Kim WH, Kim HH, Lee HJ, Yang HK: Laparoscopy-assisted pylorus-preserving gastrectomy is better than laparoscopy-assisted distal gastrectomy for middle-third early gastric cancer. Ann Surg 2014, 259(3):485-493. 
10. Song P, Lu M, Pu F, Zhang D, Wang B, Zhao Q: Meta-analysis of pylorus-preserving gastrectomy for middlethird early gastric cancer. Journal of Laparoendoscopic and Advanced Surgical Techniques 2014, 24(10).

11. Moher D, Liberati A, Tetzlaff J, Altman DG, Group P: Preferred reporting items for systematic reviews and meta-analyses: the PRISMA statement. Int J Surg 2010, 8(5):336-341.

12. Hozo SP, Djulbegovic B, Hozo I: Estimating the mean and variance from the median, range, and the size of a sample. BMC Med Res Methodol 2005, 5:13.

13. Isozaki H, Okajima K, Momura E, Ichinona T, Fujii K, Izumi N, Takeda Y: Postoperative evaluation of pylorus-preserving gastrectomy for early gastric cancer. Br J Surg 1996, 83(2):266-269.

14. Zhang D, Shimoyama S, Kaminishi M: Feasibility of pylorus-preserving gastrectomy with a wider scope of lymphadenectomy. Archives of surgery (Chicago, III : 1960) 1998, 133(9):993-997.

15. Hotta T, Taniguchi K, Kobayashi Y, Johata K, Sahara M, Naka T, Terashita S, Yokoyama S, Matsuyama K: Postoperative evaluation of pylorus-preserving procedures compared with conventional distal gastrectomy for early gastric cancer. Surgery today 2001, 31(9):774-779.

16. Tomita R, Fujisaki S, Tanjoh K: Pathophysiological studies on the relationship between postgastrectomy syndrome and gastric emptying function at 5 years after pylorus-preserving distal gastrectomy for early gastric cancer. World J Surg 2003, 27(6):725-733.

17. Urushihara T, Sumimoto K, Shimokado K, Kuroda Y: Gastric motility after laparoscopically assisted distal gastrectomy, with or without preservation of the pylorus, for early gastric cancer, as assessed by digital dynamic x-ray imaging. Surg Endosc 2004, 18(6):964-968.

18. Nunobe S, Sasako M, Saka M, Fukagawa T, Katai H, Sano T: Symptom evaluation of long-term postoperative outcomes after pylorus-preserving gastrectomy for early gastric cancer. Gastric Cancer 2007, 10(3):167-172.

19. Ikeguchi M, Hatada T, Yamamoto M, Miyake T, Matsunaga T, Fukuda K, Saito H, Tatebe S: Evaluation of a pylorus-preserving gastrectomy for patients preoperatively diagnosed with early gastric cancer located in the middle third of the stomach. Surgery today 2010, 40(3):228-233.

20. Lee SW, Nomura E, Bouras G, Tokuhara T, Tsunemi S, Tanigawa N: Long-Term Oncologic Outcomes from Laparoscopic Gastrectomy for Gastric Cancer: A Single-Center Experience of 601 Consecutive Resections. Journal of the American College of Surgeons 2010, 211(1):33-40.

21. Tomikawa M, Korenaga D, Akahoshi T, Kohshi K, Sugimachi K, Nagao Y, Tsutsumi N, Takenaka K, Kakeji Y, Hashizume $\mathrm{M}$ et al: Quality of life after laparoscopy-assisted pylorus-preserving gastrectomy: an evaluation using a questionnaire mailed to the patients. Surgery today 2012, 42(7):625-632.

22. Fujita J, Takahashi M, Urushihara T, Tanabe K, Kodera Y, Yumiba T, Matsumoto H, Takagane A, Kunisaki C, Nakada K: Assessment of postoperative quality of life following pylorus-preserving gastrectomy and Billroth-I distal gastrectomy in gastric cancer patients: results of the nationwide postgastrectomy syndrome assessment study. Gastric Cancer 2016, 19(1):302-311.

23. Isozaki H, Matsumoto S, Murakami S, Takama T, Sho T, Ishihara K, Sakai K, Takeda M, Nakada K, Fujiwara T: Diminished Gastric Resection Preserves Better Quality of Life in Patients with Early Gastric Cancer. Acta medica Okayama 2016, 70(2):119-130.

24. Aizawa M, Honda M, Hiki N, Kinoshita T, Yabusaki H, Nunobe S, Shibasaki H, Matsuki A, Watanabe M, Abe T: Oncological outcomes of function-preserving gastrectomy for early gastric cancer: a multicenter 
propensity score matched cohort analysis comparing pylorus-preserving gastrectomy versus conventional distal gastrectomy. Gastric Cancer 2017, 20(4):709-717.

25. Hosoda K, Yamashita K, Sakuramoto S, Katada N, Moriya H, Mieno H, Watanabe M: Postoperative quality of life after laparoscopy-assisted pylorus-preserving gastrectomy compared With laparoscopy-assisted distal gastrectomy: A cross-sectional postal questionnaire survey. Am J Surg 2017, 213(4):763-770.

26. Eom BW, Park B, Yoon HM, Ryu KW, Kim YW: Laparoscopy-assisted pylorus-preserving gastrectomy for early gastric cancer: A retrospective study of long-term functional outcomes and quality of life. World journal of gastroenterology 2019, 25(36):5494-5504.

27. Tsujiura M, Hiki N, Ohashi M, Nunobe S, Kumagai K, Ida S, Ohashi T, Sano T, Yamaguchi T: Should pyloruspreserving gastrectomy be performed for overweight/obese patients with gastric cancer? Gastric Cancer 2019, 22(6):1247-1255.

28. Kodama M, Koyama K: Indications for pylorus preserving gastrectomy for early gastric cancer located in the middle third of the stomach. World J Surg 1991, 15(5):628-633; discussion 633-624.

29. Sawai K, Takahashi T, Fujioka T, Minato H, Taniguchi H, Yamaguchi T: Pylorus-preserving gastrectomy with radical lymph node dissection based on anatomical variations of the infrapyloric artery. Am J Surg 1995, 170(3):285-288.

30. Japanese Gastric Cancer A: Japanese gastric cancer treatment guidelines 2014 (ver. 4). Gastric Cancer 2017, 20(1):1-19.

31. Kim BH, Hong SW, Kim JW, Choi SH, Yoon SO: Oncologic safety of pylorus-preserving gastrectomy in the aspect of micrometastasis in lymph nodes at stations 5 and 6. Ann Surg Oncol 2014, 21(2):533-538.

32. Kong SH, Kim JW, Lee HJ, Kim WH, Lee KU, Yang HK: The safety of the dissection of lymph node stations 5 and 6 in pylorus-preserving gastrectomy. Ann Surg Oncol 2009, 16(12):3252-3258.

33. Oh SY, Lee HJ, Yang HK: Pylorus-preserving gastrectomy for gastric cancer. Journal of gastric cancer 2016, 16(2):63-71.

34. Tokunaga M, Hiki N, Fukunaga T, Ohyama S, Yamada K, Yamaguchi T: Better prognosis of T2 gastric cancer with preoperative diagnosis of early gastric cancer. Ann Surg Oncol 2009, 16(6):1514-1519.

35. Tu RH, Lin JX, Zheng CH, Li P, Xie JW, Wang JB, Lu J, Chen QY, Cao LL, Lin M et al: Development of a nomogram for predicting the risk of anastomotic leakage after a gastrectomy for gastric cancer. Eur $\mathrm{J}$ Surg Oncol 2017, 43(2):485-492.

36. Machella TE: The Mechanism of the Post-gastrectomy "Dumping" Syndrome. Ann Surg 1949, 130(2):145159.

37. Kobayashi T, Hisanaga M, Kanehiro H, Yamada Y, Ko S, Nakajima Y: Analysis of risk factors for the development of gallstones after gastrectomy. Br J Surg 2005, 92(11):1399-1403.

38. Nabae T, Takahata S, Konomi H, Deng ZL, Yokohata K, Chijiiwa K, Tanaka M: Effect of prepyloric gastric transection and anastomosis on sphincter of Oddi cyclic motility in conscious dogs. Journal of gastroenterology 2001, 36(8):530-537.

39. Nunobe S, Hiki N, Fukunaga T, Tokunaga M, Ohyama S, Seto Y, Yamaguchi T: Laparoscopy-assisted pylorus-preserving gastrectomy: preservation of vagus nerve and infrapyloric blood flow induces less stasis. World J Surg 2007, 31(12):2335-2340. 
40. Kiyokawa T, Hiki N, Nunobe S, Honda M, Ohashi M, Sano T: Preserving infrapyloric vein reduces postoperative gastric stasis after laparoscopic pylorus-preserving gastrectomy. Langenbeck's archives of surgery 2017, 402(1):49-56.

41. Zhu CC, Kim TH, Berlth F, Park SH, Suh YS, Kong SH, Lee HJ, Cao H, Yang HK: Clinical outcomes of intraoperative manual dilatation of pylorus in pylorus-preserving gastrectomy: a retrospective analysis. Gastric Cancer 2018, 21(5):864-870.

\section{Tables}

Table 1 Details of the articles included in the meta-analysis 


\begin{tabular}{|c|c|c|c|c|c|c|c|c|c|c|c|c|}
\hline \multirow[t]{2}{*}{ References } & \multirow[t]{2}{*}{ Approach } & \multirow[t]{2}{*}{ Age } & \multirow[t]{2}{*}{$\operatorname{Sex}(m / f)$} & \multirow[t]{2}{*}{ BMI } & \multirow{2}{*}{$\begin{array}{l}\text { Tumor } \\
\text { size }\end{array}$} & \multicolumn{3}{|c|}{ Stage } & \multirow[t]{2}{*}{ Ananstomosis } & \multirow[t]{2}{*}{ Nerve $^{a}$} & \multirow{2}{*}{$\begin{array}{l}\text { Antral } \\
\text { cuff } \\
(\mathrm{cm})^{\mathrm{b}}\end{array}$} & \multirow{2}{*}{$\begin{array}{l}\text { Presrevation } \\
\text { of } \\
\text { LN station } \\
5^{\mathrm{C}}\end{array}$} \\
\hline & & & & & & I & II & III & & & & \\
\hline \multirow[t]{2}{*}{ Isozaki et al. $^{2}$} & CDG 14 & 52.7 & $11 / 3$ & NA & NA & NA & NA & NA & NA & & & \\
\hline & PPG 15 & 57.3 & $10 / 5$ & NA & NA & NA & NA & NA & Gastro-gastro & $\begin{array}{l}\text { Hepatic, } \\
\text { pyloric }\end{array}$ & 1.5 & Yes \\
\hline \multirow[t]{2}{*}{ Imada et al. ${ }^{3}$} & CDG 25 & NA & NA & NA & NA & NA & NA & NA & NA & & & \\
\hline & PPG 20 & NA & NA & NA & NA & NA & NA & NA & NA & $\begin{array}{l}\text { Hepatic, } \\
\text { pyloric }\end{array}$ & 1.5 & Yes \\
\hline \multirow[t]{2}{*}{ Zhang et al. ${ }^{4}$} & CDG 28 & $58.0 \pm 17.1$ & $21 / 7$ & NA & NA & 28 & 0 & 0 & BI & & & \\
\hline & PPG 15 & $58.9 \pm 9.4$ & $11 / 4$ & NA & NA & 15 & 0 & 0 & Gastro-gastro & $\begin{array}{l}\text { Hepatic, } \\
\text { pyloric, } \\
\text { celiac }\end{array}$ & 1.5 & No \\
\hline \multirow[t]{2}{*}{ Hotta et al. ${ }^{5}$} & CDG 45 & NA & NA & NA & NA & 45 & 0 & 0 & BI & & & \\
\hline & PPG 19 & NA & NA & NA & NA & 19 & 0 & 0 & Gastro-gastro & $\begin{array}{l}\text { Hepatic, } \\
\text { pyloric }\end{array}$ & 1.5 & Yes \\
\hline \multirow[t]{2}{*}{ Tomita et al. ${ }^{6}$} & CDG 22 & NA & NA & NA & NA & NA & NA & NA & NA & & & \\
\hline & PPG 10 & NA & NA & NA & NA & NA & NA & NA & NA & $\begin{array}{l}\text { Hepatic, } \\
\text { pyloric }\end{array}$ & 1.5 & No \\
\hline \multirow{2}{*}{$\begin{array}{l}\text { Shibata } \\
\text { al. }{ }^{7}\end{array}$} & CDG 38 & $60 \pm 2$ & $25 / 13$ & NA & NA & 36 & 0 & 0 & BI & & & \\
\hline & PPG 36 & $64 \pm 1$ & $23 / 13$ & NA & NA & 38 & 0 & 0 & Gastro-gastro & NA & 1.5 & No \\
\hline \multirow{2}{*}{$\begin{array}{l}\text { Urushihara et } \\
\text { al. }^{8}\end{array}$} & LADG 26 & 68 & $15 / 11$ & NA & NA & 26 & 0 & 0 & NA & & & \\
\hline & LAPPG 26 & 68 & $14 / 12$ & $\mathrm{NA}$ & NA & 25 & 1 & 0 & Gastro-gastro & $\begin{array}{l}\text { Hepatic, } \\
\text { pyloric }\end{array}$ & 3 & NA \\
\hline \multirow{2}{*}{$\begin{array}{l}\text { Nunobe } \\
\text { al. }{ }^{9}\end{array}$} & CDG 203 & NA & $127 / 76$ & NA & NA & NA & NA & NA & BI & & & \\
\hline & PPG 194 & NA & $121 / 73$ & NA & NA & NA & NA & NA & Gastro-gastro & $\begin{array}{l}\text { Hepatic, } \\
\text { pyloric, } \\
\text { celiac }\end{array}$ & $\begin{array}{l}2.5- \\
6.0\end{array}$ & No \\
\hline \multirow[t]{2}{*}{ Park et al. ${ }^{10}$} & CDG 17 & $56.2 \pm 9.4$ & $13 / 4$ & NA & NA & 17 & 0 & 0 & BI & & & \\
\hline & PPG 22 & $57.3 \pm 9.5$ & $18 / 4$ & NA & NA & 22 & 0 & 0 & Gastro-gastro & $\begin{array}{l}\text { Hepatic, } \\
\text { pyloric }\end{array}$ & 3 & No \\
\hline \multirow{2}{*}{$\begin{array}{l}\text { Ikeguchi } \\
\text { al. }{ }^{11}\end{array}$} & CDG 87 & 64.2 & $56 / 31$ & NA & 3.1 & 79 & 6 & 2 & BI & & & \\
\hline & PPG 46 & 62.8 & $24 / 22$ & NA & 2.6 & 46 & 0 & 0 & Gastro-gastro & $\begin{array}{l}\text { Hepatic, } \\
\text { pyloric }\end{array}$ & 3 & Yes \\
\hline \multirow[t]{2}{*}{ Lee et al. ${ }^{12}$} & CDG 305 & NA & NA & NA & NA & NA & NA & NA & NA & & & \\
\hline & PPG 148 & $\mathrm{NA}$ & NA & NA & NA & NA & NA & NA & NA & NA & 4 & $\mathrm{NA}$ \\
\hline \multirow{2}{*}{$\begin{array}{l}\text { Tomikawa et } \\
\text { al. }^{13}\end{array}$} & LADG 12 & $68.7 \pm 4.8$ & $6 / 6$ & BW & 2.6 & NA & NA & NA & Gastroduodenal & & & \\
\hline & LAPPG 9 & $69.2 \pm 6.9$ & $6 / 3$ & NA & 3.9 & NA & NA & NA & Gastro-gastro & $\begin{array}{l}\text { Hepatic, } \\
\text { pyloric, } \\
\text { celiac }\end{array}$ & 3 & Yes \\
\hline \multirow[t]{2}{*}{ Suh et al. ${ }^{14}$} & LADG 176 & $59.1 \pm 12.0$ & $107 / 69$ & $24.0 \pm 3.1$ & $2.3 \pm 1.2$ & 166 & 10 & 0 & $\begin{array}{l}\text { BI } 162+\text { BII } 13 \\
+ \text { RY } 1\end{array}$ & & & \\
\hline & $\begin{array}{l}\text { LAPPG } \\
116\end{array}$ & $54.1 \pm 12.3$ & $55 / 61$ & $23.3 \pm 3.0$ & $2.6 \pm 1.2$ & 108 & 7 & 1 & Gastro-gastro & NA & NA & NA \\
\hline Fujita et al. ${ }^{15}$ & CDG 909 & $61.6 \pm 9.1$ & $594 / 311$ & $22.7 \pm 3.0$ & NA & NA & NA & NA & BI & & & \\
\hline & PPG 313 & $61.5 \pm 8.7$ & $183 / 126$ & $22.7 \pm 3.0$ & NA & NA & NA & NA & Gastro-gastro & NA & NA & NA \\
\hline Isozaki & CDG 21 & $61.0 \pm 10.0$ & $17 / 8$ & NA & $3.2 \pm 1.6$ & 25 & 0 & 0 & BI $21+$ RY 4 & & & \\
\hline & PPG 15 & $61.2 \pm 12.4$ & $6 / 9$ & NA & $2.5 \pm 9.9$ & 15 & 0 & 0 & Gastro-gastro & $\begin{array}{l}\text { Hepatic, } \\
\text { pyloric, } \\
\text { celiac }\end{array}$ & 4 & NA \\
\hline $\begin{array}{l}\text { Aizawa et } \\
\text { al. }{ }^{17}\end{array}$ & CDG 502 & $61.7 \pm 11.4$ & $309 / 193$ & $22.6 \pm 3.08$ & $27.3 \pm 12.5$ & 502 & 0 & 0 & $\begin{array}{l}\text { BI } 334+\text { BII } 2 \\
+ \text { RY } 166\end{array}$ & & & \\
\hline & PPG 502 & $60.7 \pm 9.6$ & $301 / 201$ & $22.7 \pm 3.14$ & $27.4 \pm 12.7$ & 502 & 0 & 0 & Gastro-gastro & NA & NA & NA \\
\hline Hosoda et & LADG 32 & $63.2 \pm 8.8$ & $13 / 19$ & $22.5 \pm 3.2$ & $2.8 \pm 1.7$ & 31 & 0 & 1 & NA & & & \\
\hline & LAPPG 32 & $64.0 \pm 9.5$ & $13 / 19$ & $22.7 \pm 2.6$ & $2.9 \pm 1.5$ & 30 & 2 & 0 & NA & $\begin{array}{l}\text { Hepatic, } \\
\text { pyloric, } \\
\text { celiac }\end{array}$ & 4 & Yes \\
\hline Eom et al. ${ }^{19}$ & $\begin{array}{l}\text { LADG } 195 \\
\text { LAPPG101 }\end{array}$ & $\begin{array}{l}56.5 \pm 11.8 \\
58.3 \pm 12.0\end{array}$ & $\begin{array}{l}114 / 81 \\
54 / 47\end{array}$ & $\begin{array}{l}24.0 \pm 3.1 \\
24.1 \pm 3.1\end{array}$ & $\begin{array}{l}2.8 \pm 1.5 \\
2.5 \pm 1.4\end{array}$ & $\begin{array}{l}195 \\
101\end{array}$ & $\begin{array}{l}0 \\
0\end{array}$ & $\begin{array}{l}0 \\
0\end{array}$ & $\begin{array}{l}\text { BII } \\
\text { Gastro-gastro }\end{array}$ & Hepatic, & $3-5$ & Yes \\
\hline
\end{tabular}




\begin{tabular}{|c|c|c|c|c|c|c|c|c|c|c|c|c|}
\hline \multirow{3}{*}{$\begin{array}{l}\text { Tsujiura } \\
\text { al. }^{20}\end{array}$} & & & & & & & & & & \multicolumn{3}{|l|}{ pyloric } \\
\hline & LADG 101 & $59.4 \pm 11.1$ & $72 / 29$ & $27.0 \pm 2.3$ & NA & NA & NA & NA & BI 43 + RY 58 & & & \\
\hline & LPPG 101 & $59.5 \pm 9.3$ & $71 / 30$ & $27.1 \pm 2.3$ & NA & NA & NA & NA & Gastro-gastro & \multirow[t]{2}{*}{$\begin{array}{l}\text { Hepatic, } \\
\text { pyloric }\end{array}$} & \multirow[t]{2}{*}{ NA } & \multirow[t]{2}{*}{ Yes } \\
\hline \multirow[t]{2}{*}{ Xia et al. ${ }^{21}$} & LADG 97 & $57.5 \pm 12.1$ & $63 / 34$ & $22.7 \pm 4.8$ & $1.8 \pm 0.7$ & 97 & 0 & 0 & BI & & & \\
\hline & LAPPG 70 & $56.8 \pm 10.9$ & $46 / 24$ & $22.3 \pm 2.3$ & $1.8 \pm 0.7$ & 70 & 0 & 0 & Gastro-gastro & \multirow[t]{2}{*}{$\begin{array}{l}\text { Hepatic, } \\
\text { pyloric }\end{array}$} & \multirow[t]{2}{*}{3} & \multirow[t]{2}{*}{ Yes } \\
\hline \multirow[t]{2}{*}{ Zhu et al. ${ }^{22}$} & CDG 61 & NA & $34 / 27$ & NA & NA & 56 & 4 & 1 & BII 24 + RY 37 & & & \\
\hline & PPG 145 & NA & $67 / 78$ & NA & NA & 138 & 4 & 3 & Gastro-gastro & NA & 3 & Yes \\
\hline
\end{tabular}

a Preservation of the branches of vagus nerve in pylorus-preserving gastrectomy (PPG); b Length of the antral cuff in PPG; c Preservation of lymph nodes (LN) station 5 in PPG; LADG, laparoscopic-assisted distal gastrectomy; LAPPG, laparoscopic-assisted pylorus-preserving gastrectomy; CDG, conventional distal gastrectomy; BI, Billroth I; BII, Billroth II; R-Y, Roux-en-Y; Gastro-gastro, Gastrogastrostomy; NA, not applicable.

Table 2 Overall results comparing PPG with DG

\begin{tabular}{|c|c|c|c|c|c|c|}
\hline & \multirow[t]{2}{*}{ No. of studies } & \multirow[t]{2}{*}{ OR/WMD (95\%CI) } & \multirow[t]{2}{*}{$\mathrm{P}$} & \multicolumn{2}{|c|}{ Heterogeneity } & \multirow[t]{2}{*}{ Effect model } \\
\hline & & & & $\overline{\mathrm{I}^{2}}$ & $P$ & \\
\hline Age & 12 & $0.19(-1.71,2.09)$ & 0.845 & 87.90 & 0.000 & Random \\
\hline Gender & 17 & $0.83(0.73,0.94)$ & 0.005 & 0.00 & 0.876 & Fixed \\
\hline BMI $\left(\mathrm{kg} / \mathrm{m}^{2}\right)$ & 7 & $-0.02(-0.24,0.19)$ & 0.828 & 0.00 & 0.587 & Fixed \\
\hline Tumor size $(\mathrm{cm})$ & 6 & $0.02(-0.09,0.13)$ & 0.767 & 31.50 & 0.200 & Fixed \\
\hline Operation time (min) & 9 & $-5.00(-13.53,3.54)$ & 0.251 & 76.30 & 0.000 & Random \\
\hline Blood loss (ml) & 7 & $-19.85(-45.14,5.44)$ & 0.124 & 74.90 & 0.001 & Random \\
\hline Proximal resection margin $(\mathrm{cm})$ & 4 & $-0.47(-0.91,-0.03)$ & 0.038 & 74.30 & 0.009 & Random \\
\hline Distal resection margin $(\mathrm{cm})$ & 4 & $-2.76(-4.96,-0.57)$ & 0.013 & 98.20 & 0.000 & Random \\
\hline Retrieved lymph nodes & 8 & $-1.10(-2.18,0.01)$ & 0.048 & 8.70 & 0.363 & Fixed \\
\hline Postoperative hospital stay (day) & 8 & $0.98(0.66,1.29)$ & 0.000 & 30.60 & 0.184 & Fixed \\
\hline Complications & 12 & $0.97(0.76,1.25)$ & 0.835 & 5.70 & 0.389 & Fixed \\
\hline Anastomotic leakage & 10 & $0.49(0.24,0.97)$ & 0.041 & 0.00 & 0.946 & Fixed \\
\hline Gastritis & 8 & $0.22(0.07,0.74)$ & 0.014 & 71.30 & 0.001 & Random \\
\hline Esophagitis & 4 & $1.21(0.56,2.61)$ & 0.621 & 37.90 & 0.185 & Fixed \\
\hline Bile reflux & 6 & $0.30(0.10,0.89)$ & 0.031 & 57.90 & 0.037 & Random \\
\hline Early dumping syndrome & 4 & $0.18(0.07,0.44)$ & 0.000 & 0.00 & 0.982 & Fixed \\
\hline Gallbladder stones & 6 & $0.63(0.38,1.03)$ & 0.063 & 14.60 & 0.320 & Fixed \\
\hline Gastric stasis & 11 & $1.88(1.23,2.87)$ & 0.003 & 38.40 & 0.093 & Fixed \\
\hline Gastric emptying times $(50 \%, \mathrm{~min})$ & 3 & $8.86(1.71,16.00)$ & 0.015 & 0.00 & 0.433 & Fixed \\
\hline Total protein* & 7 & $0.39(0.25,0.53)$ & 0.000 & 34.60 & 0.164 & Fixed \\
\hline Albumin* & 7 & $0.31(0.17,0.44)$ & 0.000 & 22.00 & 0.261 & Fixed \\
\hline Hemoglobin* & 5 & $0.55(0.39,0.71)$ & 0.000 & 0.00 & 0.576 & Fixed \\
\hline Body weight loss (Kg) & 8 & $3.24(1.79,4.69)$ & 0.000 & 65.30 & 0.005 & Random \\
\hline Recurrence & 6 & $1.41(0.68,2.89)$ & 0.355 & 0.00 & 0.932 & Fixed \\
\hline Overall survival rate & 3 & $0.63(-0.06,1.32)$ & 0.074 & 0.00 & 0.951 & Fixed \\
\hline
\end{tabular}

${ }^{*}$ Effect size is presented by standardized mean difference (SMD); OR, Odds ratio; WMD, weight mean difference; CI, confidence interval; P < 0.05 are indicated in bold. 
Table 3 Subgroup-analysis by publish year, study design and type of the procedure

\begin{tabular}{|c|c|c|c|c|c|c|}
\hline \multirow[b]{2}{*}{ Items } & \multirow[b]{2}{*}{$\mathrm{n}$} & \multirow[b]{2}{*}{ OR/WMD (95\%CI) } & \multicolumn{2}{|c|}{ Test for Overall Effect } & \multicolumn{2}{|c|}{ Test for Heterogeneity } \\
\hline & & & $\mathrm{Z}$ & $\mathrm{P}$ & $\mathrm{I} 2$ & $\mathrm{P}$ \\
\hline \multicolumn{7}{|l|}{ Operative time } \\
\hline Before2010 & 3 & $-8.22(-23.46,7.01)$ & 1.06 & 0.290 & 51.4 & 0.128 \\
\hline After2010 & 6 & $-3.28(-14.91,8.35)$ & 0.55 & 0.580 & 76.6 & 0.001 \\
\hline Retrospective cohort study & 7 & $-2.11(-13.82,9.60)$ & 0.35 & 0.724 & 75.3 & 0.000 \\
\hline Prospective cohort study & 2 & $-11.9(-16.08,-7.72)$ & 5.58 & 0.000 & 0.0 & 0.839 \\
\hline Laparoscopic & 5 & $-8.08(-22.21,6.05)$ & 1.12 & 0.262 & 69.2 & 0.011 \\
\hline Open & 4 & $-1.25(-15.59,13.09)$ & 0.17 & 0.864 & 85.5 & 0.000 \\
\hline \multicolumn{7}{|l|}{ Blood loss } \\
\hline Before 2010 & 2 & $-45.69(-94.15,2.77)$ & 1.85 & 0.065 & 74.0 & 0.050 \\
\hline After2010 & 5 & $-5.16(-17.47,7.15)$ & 0.82 & 0.411 & 0.0 & 0.612 \\
\hline Retrospective cohort study & 5 & $-4.45(-16.88,7.98)$ & 0.70 & 0.483 & 0.0 & 0.688 \\
\hline Prospective cohort study & 2 & $-47.51(-91.21,-3.81)$ & 2.13 & 0.033 & 72.7 & 0.056 \\
\hline Laparoscopic & 4 & $-3.6(-17.44,10.24)$ & 0.51 & 0.610 & 0.0 & 0.535 \\
\hline Open & 3 & $-33.53(-73.60,6.53)$ & 1.64 & 0.101 & 81.6 & 0.004 \\
\hline \multicolumn{7}{|l|}{ Gastritis } \\
\hline Before 2010 & 7 & $0.22(0.06,0.79)$ & 2.31 & 0.021 & 75.0 & 0.001 \\
\hline After2010 & 1 & $0.23(0.01,6.09)$ & 0.89 & 0.376 & NA & NA \\
\hline Retrospective cohort study & 6 & $0.16(0.07,0.40)$ & 3.98 & 0.000 & 13.9 & 0.325 \\
\hline Prospective cohort study & 2 & $0.88(0.13,5.88)$ & 0.13 & 0.898 & 45.9 & 0.174 \\
\hline Laparoscopic & 1 & $0.23(0.01,6.09)$ & 0.89 & 0.376 & NA & NA \\
\hline Open & 7 & $0.22(0.06,0.79)$ & 2.31 & 0.021 & 75.0 & 0.001 \\
\hline \multicolumn{7}{|l|}{ Delayed gastric emptying } \\
\hline Before2010 & 2 & $0.64(0.21,1.96)$ & 0.79 & 0.430 & 0.0 & 0.832 \\
\hline After2010 & 9 & $2.26(1.43,3.59)$ & 3.46 & 0.001 & 34.6 & 0.141 \\
\hline Retrospective cohort study & 9 & $1.81(1.11,2.95)$ & 2.39 & 0.017 & 47.1 & 0.057 \\
\hline Prospective cohort study & 2 & $2.10(0.91,4.87)$ & 1.74 & 0.082 & 0.0 & 0.338 \\
\hline Laparoscopic & 7 & $3.03(1.60,5.73)$ & 3.41 & 0.001 & 26.3 & 0.228 \\
\hline Open & 4 & $1.23(0.69,2.20)$ & 0.69 & 0.492 & 32.0 & 0.220 \\
\hline Length $\square 3 \mathrm{~cm}$ & 1 & $0.56(0.12,2.72)$ & 0.72 & 0.474 & NA & NA \\
\hline Length $\square 3 \mathrm{~cm}$ & 7 & $2.34(1.33,4.13)$ & 2.94 & 0.003 & 28.6 & 0.210 \\
\hline Length NA & 3 & $1.70(0.84,2.84)$ & 1.48 & 0.138 & 60.3 & 0.080 \\
\hline \multicolumn{7}{|l|}{ Body weight change } \\
\hline Before2010 & 5 & $3.69(2.53,4.84)$ & 6.26 & 0.000 & 0.0 & 0.429 \\
\hline After2010 & 3 & $2.22(0.02,4.43)$ & 1.97 & 0.048 & 66.5 & 0.050 \\
\hline Retrospective cohort study & 7 & $3.18(1.54,4.83)$ & 3.79 & 0.000 & 63.2 & 0.012 \\
\hline Prospective cohort study & 1 & $3.70(2.02,5.38)$ & 4.31 & 0.000 & NA & NA \\
\hline Laparoscopic & 1 & $2.10(0.06,4.14)$ & 2.02 & 0.043 & NA & NA \\
\hline Open & 7 & $3.58(1.84,5.33)$ & 4.03 & 0.000 & 70.3 & 0.003 \\
\hline
\end{tabular}

OR, Odds ratio; WMD, weight mean difference; CI, confidence interval; NA, not applicable; $\mathrm{P}<0.05$ are indicated in bold.

\section{Supplemental Information Note}

Additional file 2 Forest plot of each outcome.

(a) Age; (b) Sex; (c) BMl; (d) Tumor size; (e) PRM; (f) DRM; PRM, proximal resection margin; DRM, distal resection margin

Additional file 4 Forest plot of each outcome. 
(a) Gastritis; (b) Esophagitis; (c) Bile reflux; (d) Early dumping syndrome; (e) Time to half gastric emptying Additional file 5 Forest plot of each outcome.

(a) Survival rate; (b) Recurrence

Additional file 6 Funnel plots comparing (a) Gastritis, (b) Esophagitis, (c) Bile reflux, (d) Early dumping.

Additional file 7 Galbraith plots comparing (a) Operative time, (b) Blood loss, (c) Number of retrieved lymph nodes, (d) Hospital day, (e) Postoperative complication, (f) Anastomotic leakage.

Additional file 8 Galbraith plots comparing (a) Delay gastric emptying, (b) Gallstone, (c) Total protein, (d) Albumin, (e) Hemoglobin, (f) Body weight loss.

Additional file 9 Galbraith plots comparing (a) Gastritis, (b) Esophagitis, (c) Bile reflux, (d) Early dumping syndrome.

\section{Literature Search}

\section{Pubmed}

)(((()(((()((()(((((Neoplasm, Stomach) OR Stomach Neoplasm) OR Neoplasms, Stomach) OR Gastric Neoplasms) OR Gastric Neoplasm) OR Neoplasm, Gastric) OR Neoplasms, Gastric) OR Cancer of Stomach) OR Stomach Cancers) OR Gastric Cancer) OR Cancer, Gastric) OR Cancers, Gastric) OR Gastric Cancers) OR Stomach Cancer) OR Cancer, Stomach) OR Cancers, Stomach) OR Cancer of the Stomach) OR Gastric Cancer, Familial Diffuse) OR "Stomach Neoplasms"[Mesh])) AND ((((((((pylorus[Title/Abstract]) OR pyloruspreserving[Title/Abstract]) OR functional-preserving[Title/Abstract]) OR pylorus preserving[Title/Abstract]) OR functional preserving[Title/Abstract]) OR function-preserving[Title/Abstract]) OR function preserving[Title/Abstract])) OR))) AND (("cohort studies"[mesh] OR "case-control studies"[mesh] OR "comparative study"[pt] OR "risk factors"[mesh] OR "cohort"[tw] OR "compared"[tw] OR "groups"[tw] OR "case control"[tw] OR "multivariate"[tw]))

\section{Cochrane}

\#1 MeSH descriptor: [Stomach Neoplasms] explode all trees

\#2 MeSH descriptor: [Neoplasms] explode all trees

\#3 MeSH descriptor: [Stomach] explode all trees

\#4 (gastric):ti,ab,kw (Word variations have been searched)

\#5 (stomach):ti,ab,kw (Word variations have been searched)

\#6 (cancer):ti,ab,kw (Word variations have been searched)

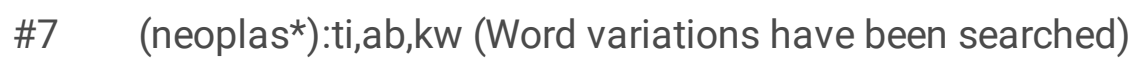


\#8 (carcinoma $\left.{ }^{\star}\right): \mathrm{ti}, \mathrm{ab}, \mathrm{kw}$ (Word variations have been searched)

\#9 \#4 OR \#5

\#10 \#6 OR \#7 OR \#8

\#11 \#9 AND \#10

\#12 \#2 AND \#3

\#13 \#1 OR \#11 OR \#12

\#14 (pylorus*):ti,ab,kw (Word variations have been searched)

\#15 \#13 AND \#14

\section{Embase}

('stomach cancer'/exp OR 'stomach neoplasm':ab,ti OR 'stomach neoplasms':ab,ti OR 'gastric neoplasms':ab,ti OR 'gastric neoplasm':ab,ti OR 'gastric cancer':ab,ti OR 'gastric cancers':ab,ti OR 'gastric cancers':ab,ti OR 'stomach cancers':ab,ti OR 'cancer of stomach':ab,ti OR 'cancer of the stomach':ab,ti) AND ('pylorus-

preserving':ab,ti OR 'pylorus preserving':ab,ti OR 'functional-preserving':ab,ti OR 'functional preserving':ab,ti OR 'function-preserving':ab,ti OR 'function preserving':ab,ti) AND ('gastrectomy'/exp OR ('gastrectomies':ab,ti OR 'gastrectomy':ab,ti))

\section{Figures}



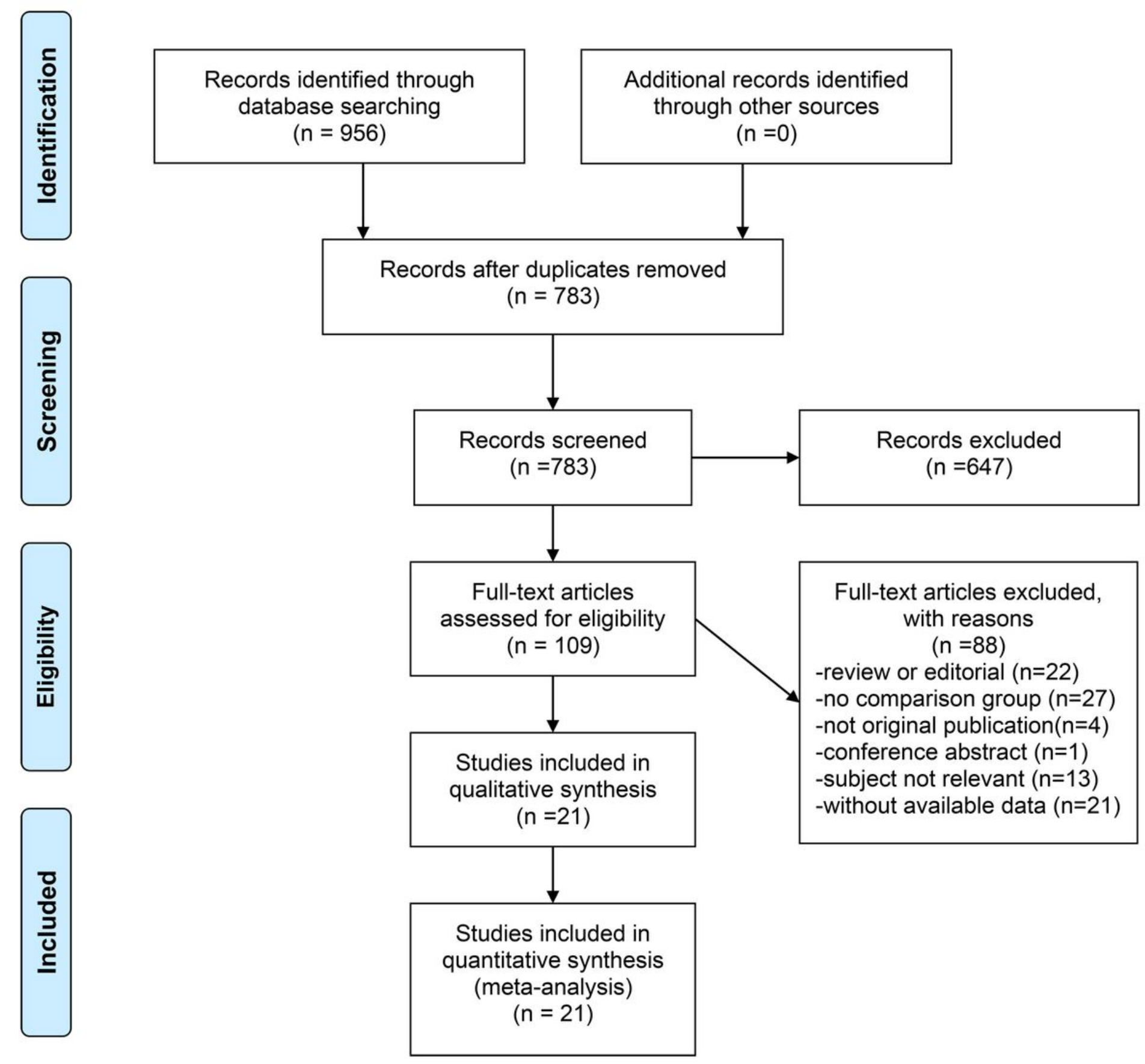

Figure 1

PRISMA diagram showing criteria for inclusion and exclusion. 
A Operative time

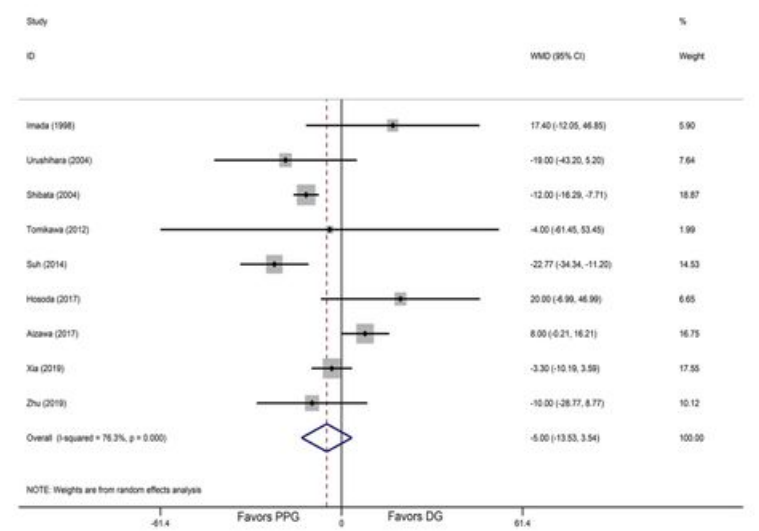

C Number of retrieved lymph nodes

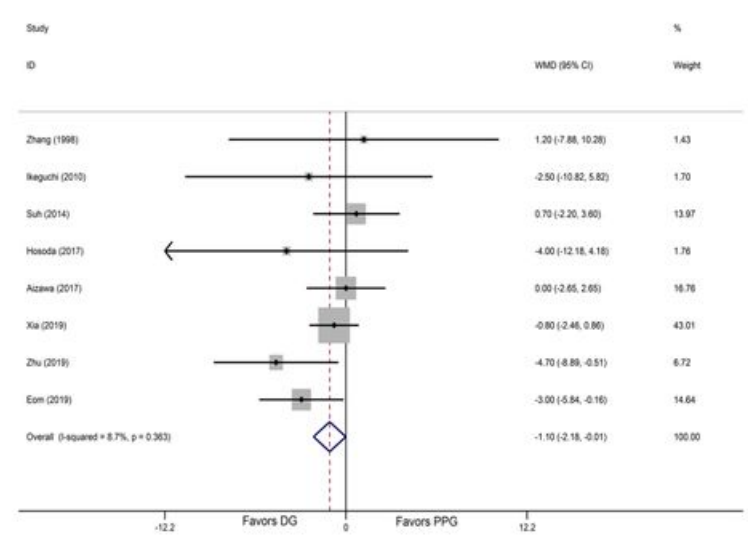

\section{E Postoperative complication}

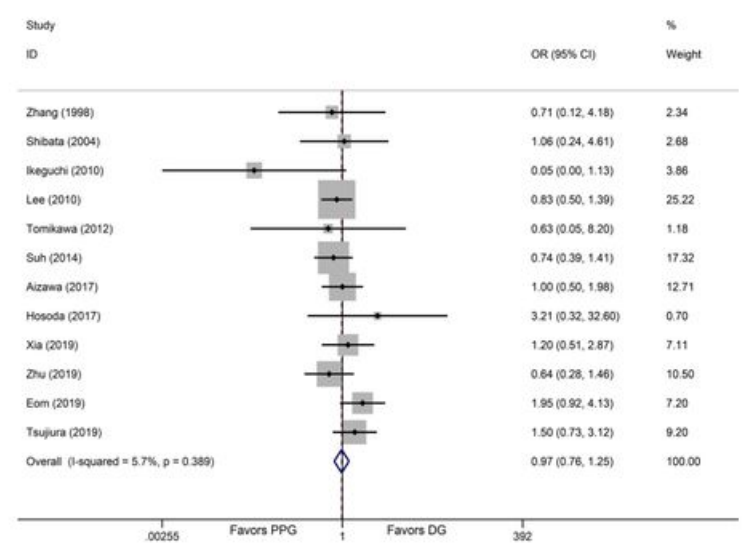

B Blood loss

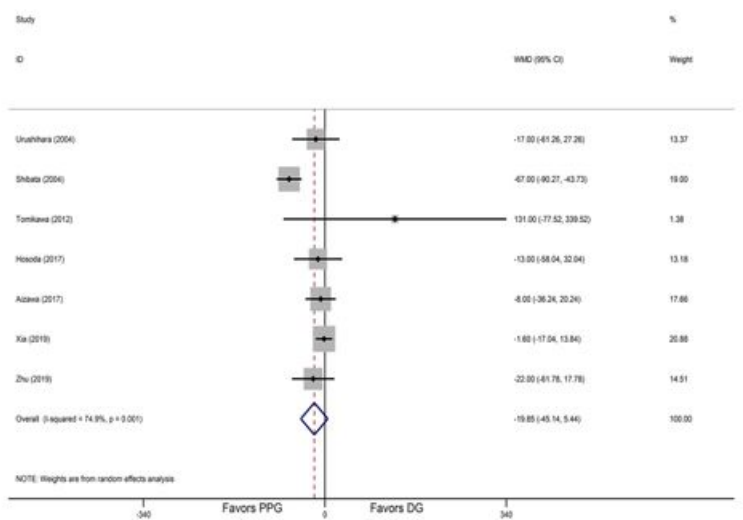

D Hospital day

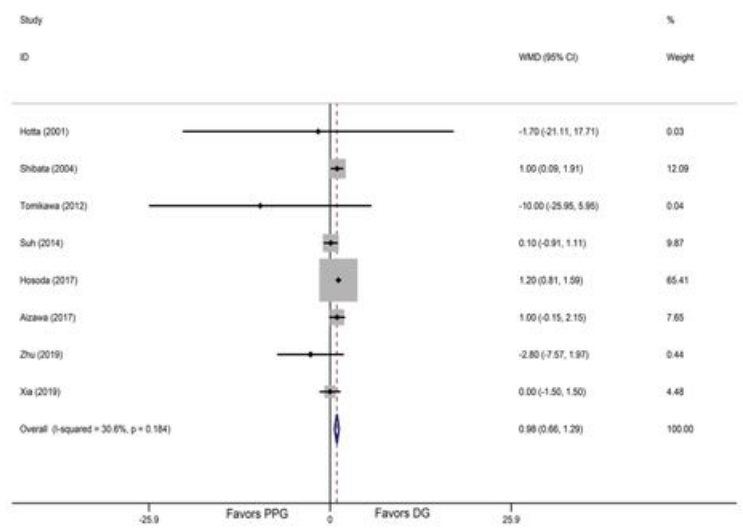

F Anastomotic leakage

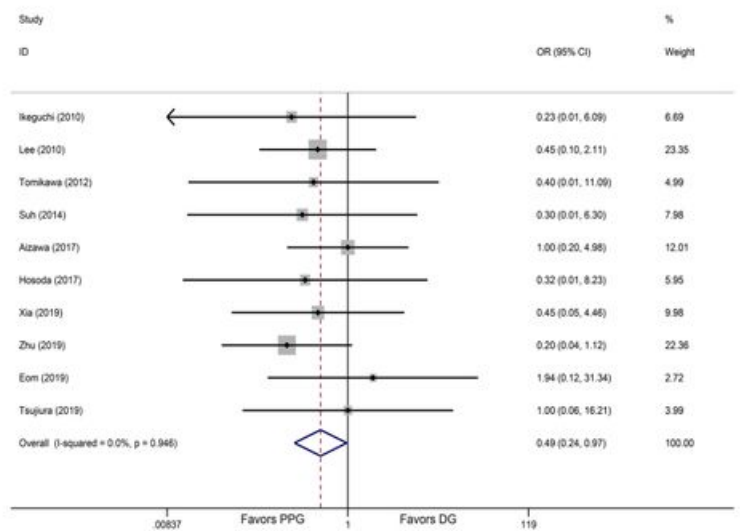

\section{Figure 2}

Forest plot of each outcome. a Operative time; b Blood loss; c Number of retrieved lymph nodes; d Hospital day; e Postoperative complication; f Anastomotic leakage 
A Delayed gastric emptying

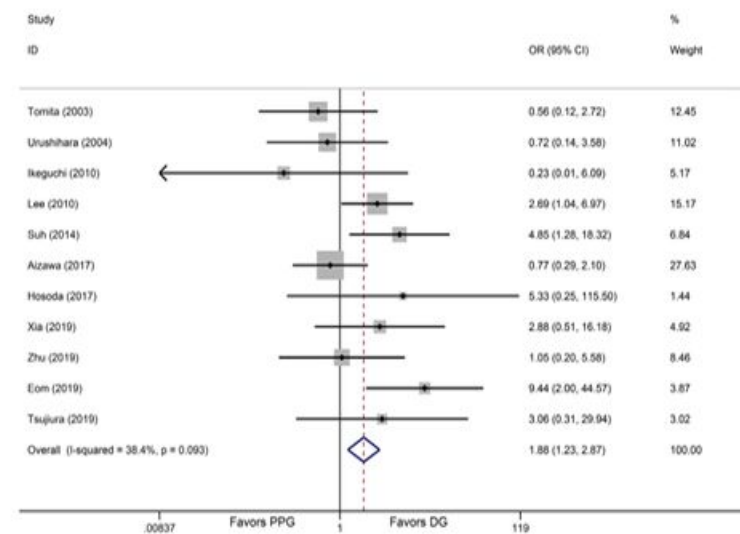

C Total protein

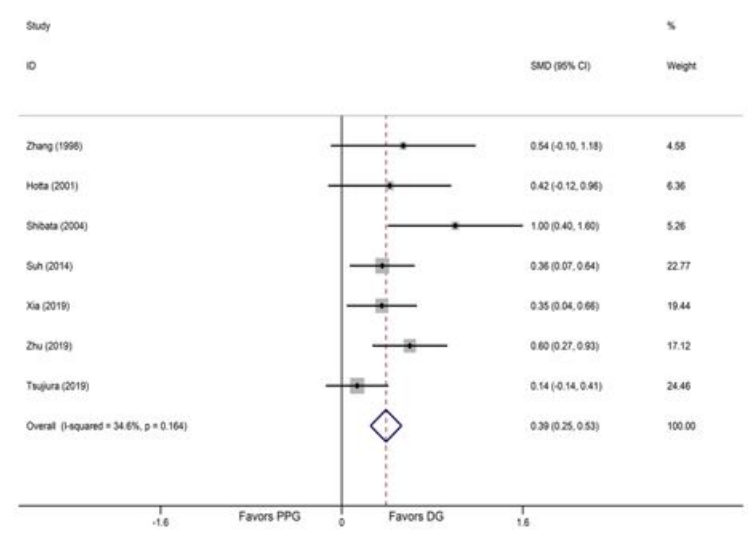

\section{E Hemoglobin}

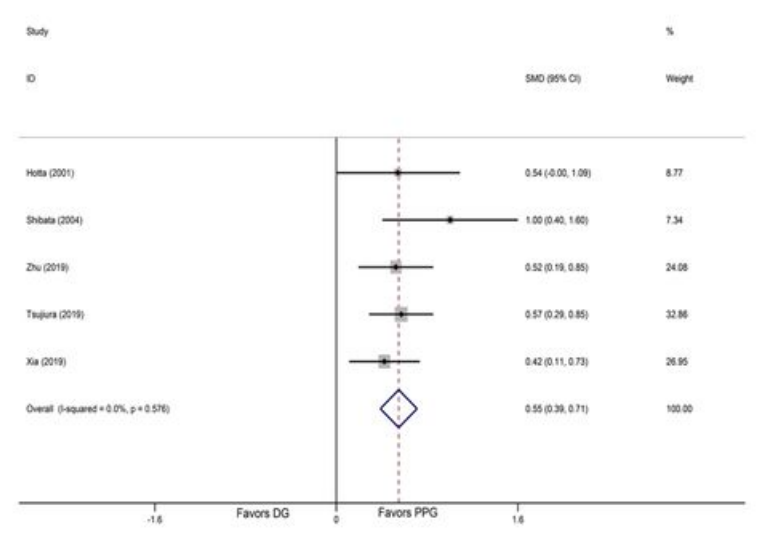

B Gallstone

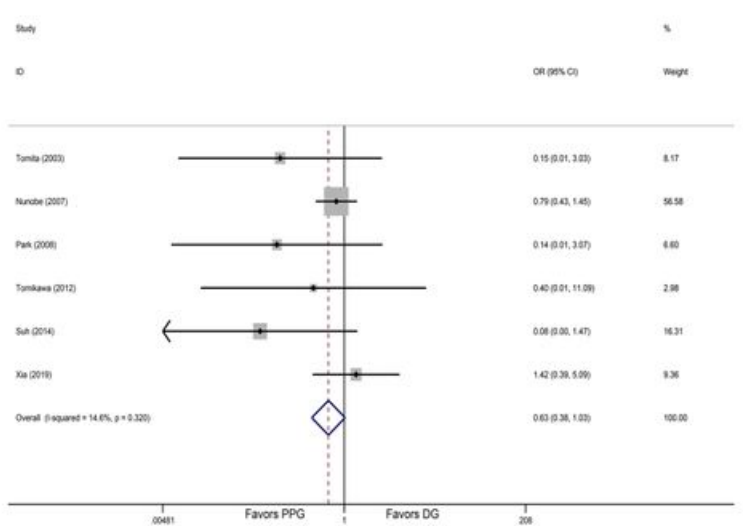

D Albumin

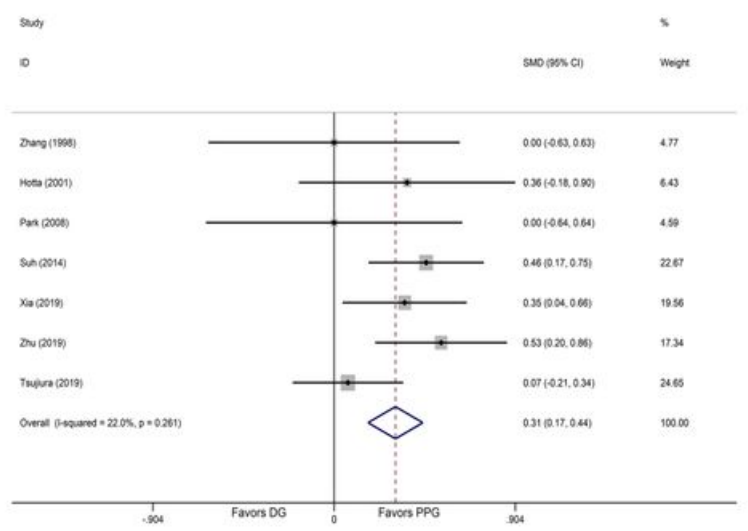

F Body weight loss

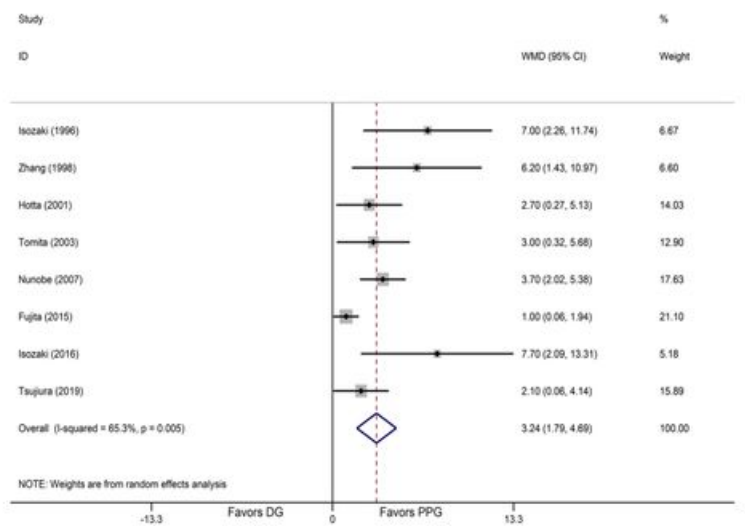

\section{Figure 3}

Forest plot of each outcome. a Delay gastric emptying; b Gallstone; c Total protein; d Albumin; e Hemoglobin; $f$ Body weight loss 

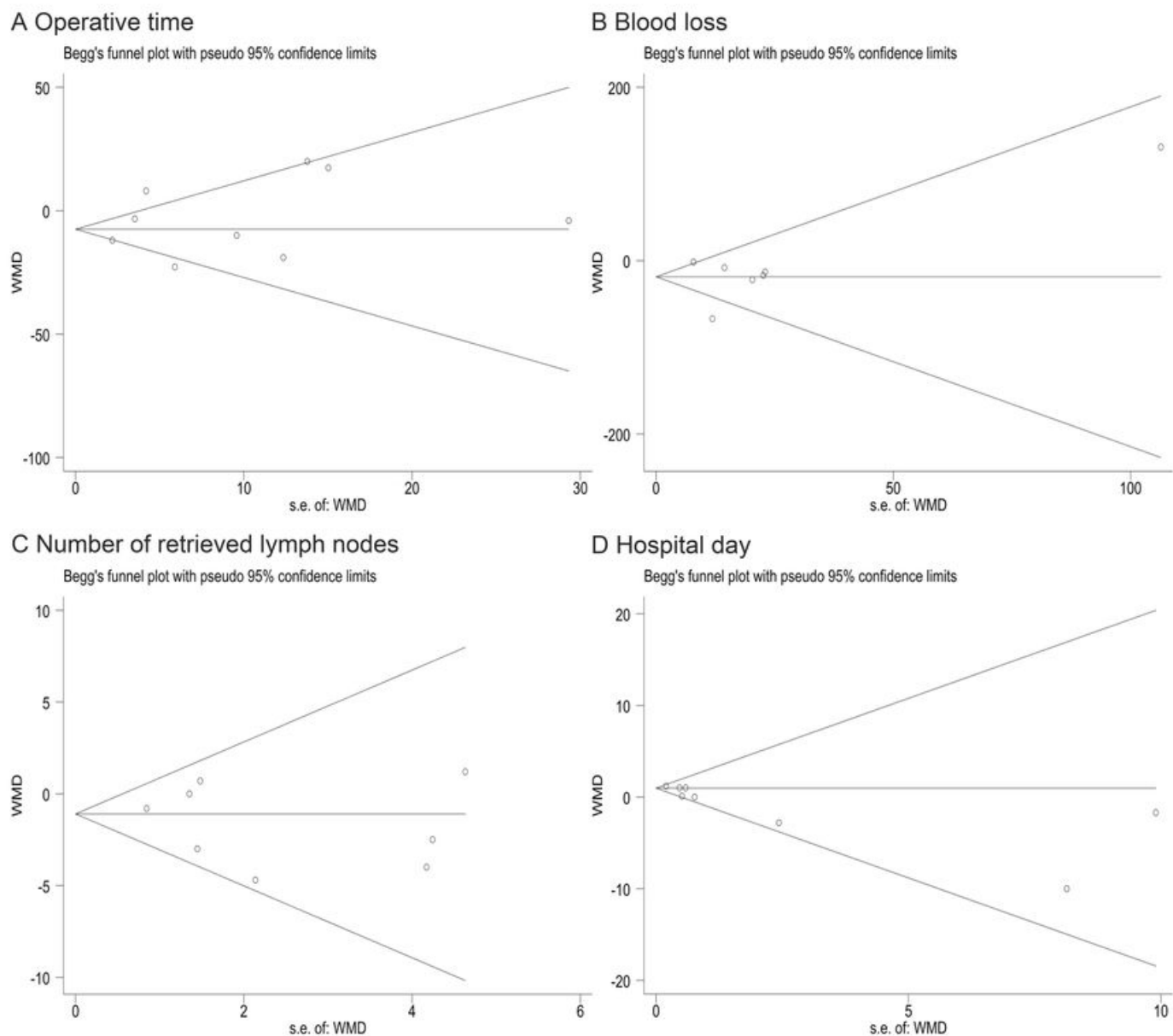

D Hospital day
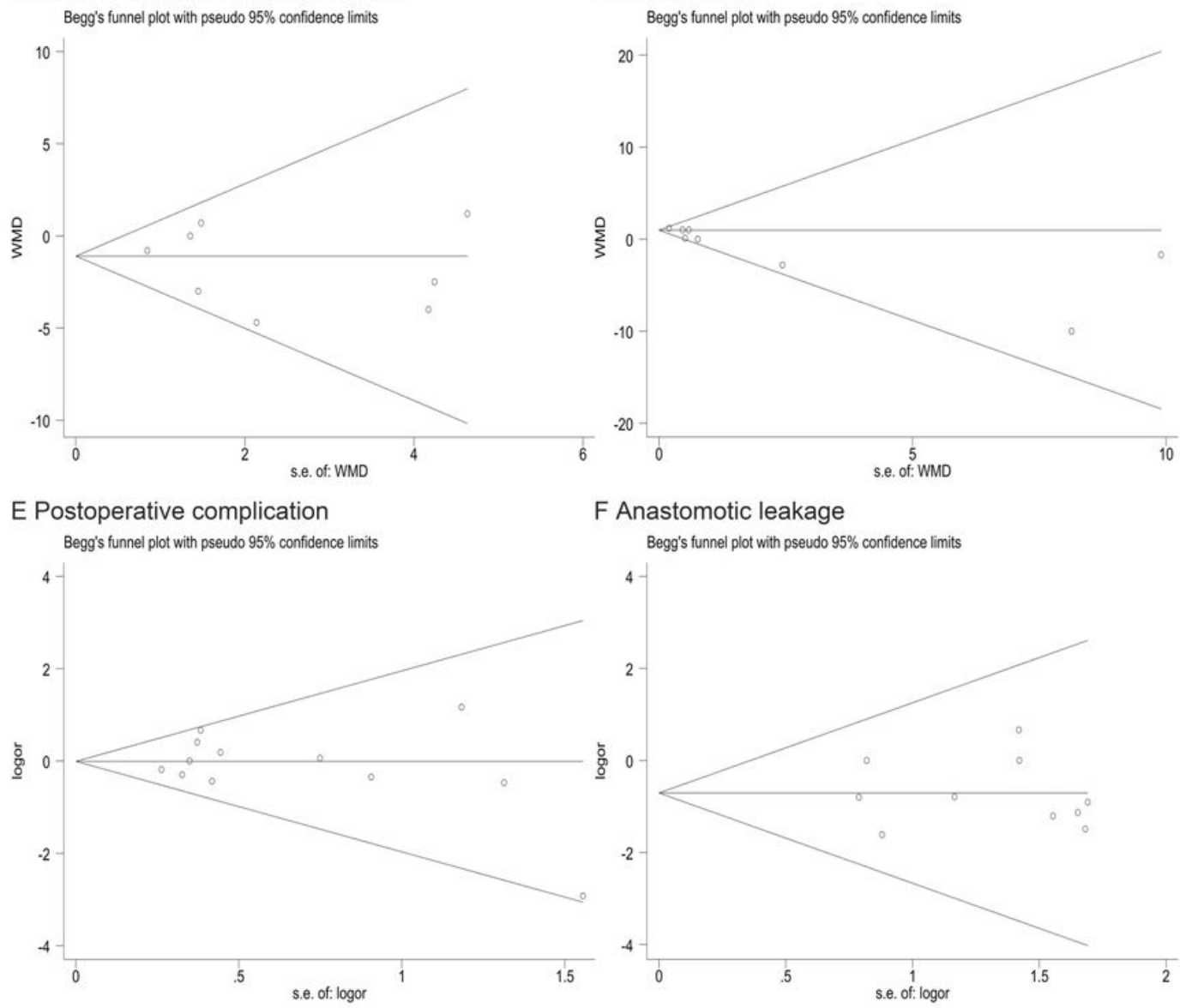

F Anastomotic leakage

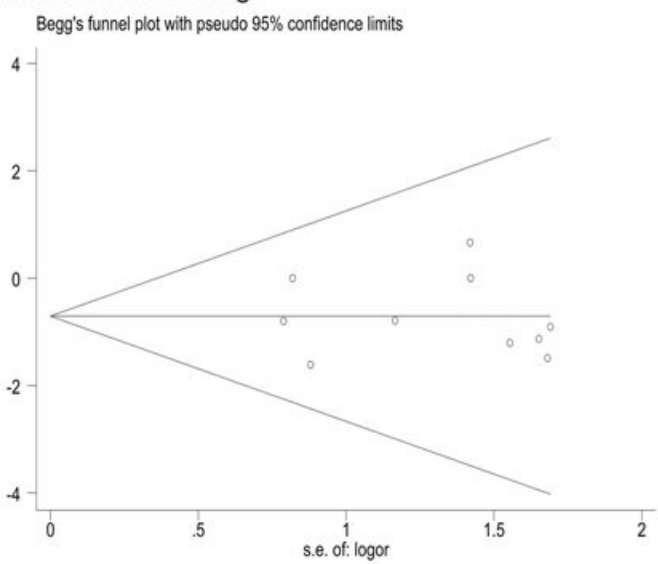

\section{Figure 4}

Funnel plots comparing (a) Operative time, (b) Blood loss, (c) Number of retrieved lymph nodes, (d) Hospital day, (e) Postoperative complication, (f) Anastomotic leakage 

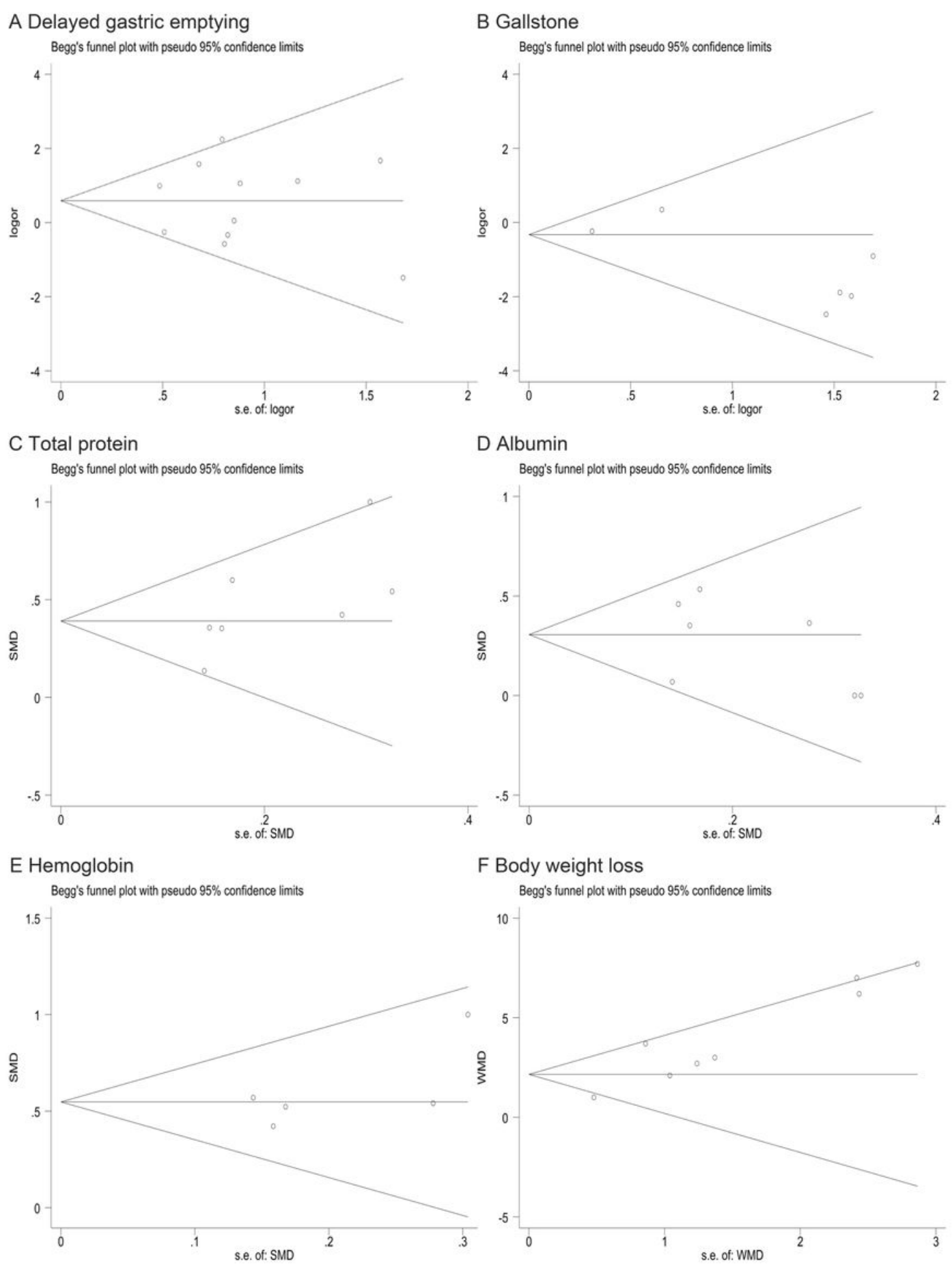

\section{Figure 5}

Funnel plots comparing (a) Delay gastric emptying, (b) Gallstone, (c) Total protein, (d) Albumin, (e) Hemoglobin, (f) Body weight loss

\section{Supplementary Files}

This is a list of supplementary files associated with this preprint. Click to download. 
- Additionalfile2.tif

- Additionalfile9.tif

- Additionalfile10.doc

- Additionalfile5.tif

- Additionalfile6.tif

- Additionalfile7.tif

- Additionalfile1.docx

- Additionalfile4.tif

- Additionalfile3.docx

- Additionalfile8.tif 